\title{
COMPARISON AND EVALUATION OF REMOTE SENSING INDICES FOR AGRICULTURAL DROUGHT MONITORING OVER KAZAKHSTAN
}

\author{
B. Sun ${ }^{1}$, J. Qian ${ }^{1, *}$, X. Chen ${ }^{1,2}$, Q. Zhou ${ }^{1,3}$ \\ ${ }^{1}$ Shenzhen Institutes of Advanced Technology, Chinese Academy of Sciences, Shenzhen, China - (sunbo, jing.qian)@ siat.ac.cn \\ ${ }^{2}$ Research Center for Ecology and Environment of Central Asia, Chinese Academy of Sciences, Urumqi, China - \\ chenxi@ms.xjb.ac.cn \\ ${ }^{3}$ Department of Geography, Hong Kong Baptist University, Hong Kong, China - qiming@ @kbu.edu.hk
}

\section{Commission III, WG III/9}

KEY WORDS: Remote Sensing Drought Index, Agricultural Drought, Crop Yield, Validation, Kazakhstan

\begin{abstract}
:
Drought has a significant impact on the Kazakhstan's agricultural economy, which is the world's largest wheat flour exporting country. Remote sensing provides an efficient tool for monitoring agricultural drought in a wide range. Hundreds of remote sensing drought indices have been developed during the past decades. Some of them have been widely used over the world as an indispensable indicator in drought monitoring systems. However, the applicability of those indices in Kazakhstan, the largest country in Central Asia has not been tested, especially for agricultural drought monitoring. In this study, the most common remote sensing drought indices in current running systems of drought monitoring are compared and evaluated. The response of those indices to the soil drought is validated based on remote sensing soil moisture data. In addition, the effectiveness of remote sensing indices in agricultural drought monitoring is assessed according to agricultural product yield data from the past 15 years (2004-2018). Results indicate that remote sensing drought indices can generally reflect serious drought events in the study area, but the consistency of different types of indices is poor. Compared with annual statistics of agricultural product yield, remote sensing drought index better reflects the long-term change of agricultural drought in Kazakhstan.
\end{abstract}

\section{INTRODUCTION}

\subsection{Background}

Kazakhstan is the largest country of Central Asia and the world's largest wheat flour exporter. It is located in the inland region of the Euro-Asian continent. As a traditional agricultural country, drought has become an important constraint that affects the country's economic development (Dubovyk et al., 2019). As an important wheat producing region in the world, Kazakhstan is listed by the United Nations Food and Agriculture Organization (FAO) as a key area of the global drought monitoring system.

Normally, drought is generally classified into four categories, namely meteorological drought, agricultural drought, hydrological drought, and socio-economic drought (Liu et al., 2016). Compared with traditional ground observations by meteorological stations, remote sensing provides an efficient tool for monitoring drought in a wide range. As the development of remote sensing technology, plant growth status represented by various vegetation indices and leaf canopy temperature have been widely monitored by integrated remote sensing sensors in drought monitoring, since they can reflect soil moisture situation (Sun et al., 2012). Because vegetation morphology and greenness as well as leaf canopy temperature are very sensitive to the drought, hundreds of remote sensing drought indices have been developed based on vegetation indices and land surface temperature (Rhee et al., 2010).

At present, the United Nations (the UN) as well as the world's major economies have developed drought monitoring systems. However, previous studies indicate that there is not a drought index that is suitable for all regions over the world (Mu, 2006).

\subsection{Objectives}

Based on the meteorological and remote sensing data, a large number of previous studies have analysed the meteorological drought situation in Central Asia (Hu et al., 2018; Ta et al., 2018; Zhang et al., 2020). However, the impact on agricultural drought such as the impact on crop product yield is unknown. In order to evaluate the applicability of remote sensing indices for agricultural drought monitoring, the most commonly used remote sensing indices in the current global drought monitoring systems are selected and compared. The effectiveness of the drought indices is examined based on crop yield statistics as well as soil moisture conditions.

\section{STUDY AREA AND DATA}

\subsection{Study Area}

Kazakhstan located in the inland region of Central Asia is chosen as the study area (Figure 1). This region is regarded as a traditional arid and semi-arid zone, because it is far away from the oceans. The mean annual precipitation is about $200-300 \mathrm{~mm}$. The crop growing season in this area is from April to October (Dubovyk et al., 2019).

As the world's largest wheat flour exporter, the majority of the grains in Kazakhstan is wheat. Due to regional climate differences, the north of Kazakhstan is a traditional wheat planting area (shadowed part in Figure 1) that accounts for more than $75 \%$ of the country's wheat products.

\footnotetext{
* Corresponding author
} 


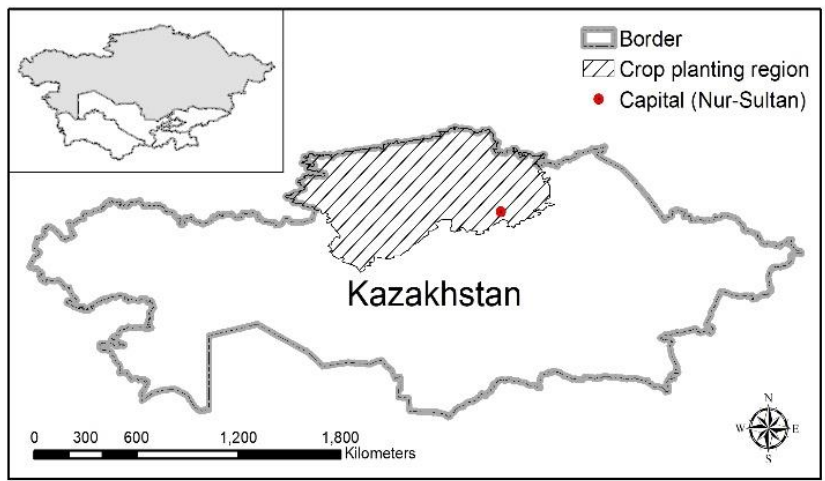

Figure 1. Location of the study area, shadowed part in the north is the traditional wheat planting area.

\subsection{Data}

The 8-day composite MODIS-VIs and MODIS-LST data at 1-km spatial resolution are utilized to generate remote sensing drought indices. For the anomaly analysis, full time series of MODIS data set from 2000 to 2019 is employed including the data set from both EOS-Terra and EOS-Aqua satellites. Besides, MODIS land cover type yearly data (MCD12Q1, $1 \mathrm{~km}$ resolution) is adopted to identify the extent of agricultural lands. Satellite-derived soil moisture observations (2010-2019) from Soil Moisture Ocean Salinity (SMOS) and Soil Moisture Active and Passive (SMAP) satellites is adopted to evaluate the utility of remote sensing drought indices. In addition, agricultural product yield data (2004-2018) from statistical yearbooks is adopted for validating the effectiveness of those indices in agricultural drought monitoring.

\section{METHODOLOGY}

Generally, different types of remote sensing drought indices are compared and evaluated by soil moisture data. The index which can best reflect soil moisture is used to monitor the long-term change of agricultural drought.

\subsection{Remote sensing drought indices}

According to the previous study, remote sensing drought indices can be categorized into several broad groups, namely, soil moisture related indices, canopy temperature related indices, vegetation water content related indices, and crop form and greenness related indices (Sun et al., 2012). Considering the indices adopted by current running drought monitoring systems, several typical remote sensing drought indices covering the above broad groups are selected for the comparison. They are Anomaly Vegetation Index (AVI), Vegetation Condition Index (VCI), Temperature Condition Index (TCI), Vegetation Health Index (VHI), and Vegetation Supply Water Index (VSWI). The formulas of the selected drought indices are shown in Table 1 as well as the data sets used. In this study, based on the 8-day composite MODIS data sets, annual mean values of Normalized Difference Vegetation Index (NDVI) and Land Surface Temperature (LST) over the growing season from April to October are adopted for the annual analysis.

\begin{tabular}{|c|c|c|}
\hline Index & Algorithm & Data \\
\hline \multirow{3}{*}{$\mathrm{AVI}$} & $\mathrm{AVI}=N D V I_{i}-\overline{N D V I}$ & MOD13A2, \\
& & $(2000-2019)$ \\
\hline
\end{tabular}

\begin{tabular}{|c|c|c|}
\hline VCI & $\mathrm{VCI}=\frac{N D V I_{i}-N D V I_{\min }}{N D V I_{\max }-N D V I_{\min }}$ & $\begin{array}{l}\text { MOD13A2, } \\
\text { MYD13A2 } \\
(2000-2019)\end{array}$ \\
\hline TCI & $\mathrm{TCI}=\frac{L S T_{i}-L S T_{\min }}{L S T_{\max }-L S T_{\min }}$ & $\begin{array}{l}\text { MOD11A2 } \\
(2000-2019)\end{array}$ \\
\hline VHI & $\mathrm{VHI}=\mathrm{a} * \mathrm{VCI}+(1-\mathrm{a}) * \mathrm{TCI}$ & $\begin{array}{l}\text { MOD13A2, } \\
\text { MYD13A2, } \\
\text { MOD11A2 } \\
(2000-2019)\end{array}$ \\
\hline $\begin{array}{l}\text { VSWI- } \\
\text { NDVI }\end{array}$ & $V S W I_{N D V I}=\frac{N D V I_{i}}{L S T_{i}}$ & $\begin{array}{l}\text { MOD13A2, } \\
\text { MOD11A2 }\end{array}$ \\
\hline $\begin{array}{l}\text { VSWI- } \\
\text { EVI }\end{array}$ & $V S W I_{E V I}=\frac{E V I_{i}}{L S T_{i}}$ & $\begin{array}{l}\text { MOD13A2, } \\
\text { MOD11A2 }\end{array}$ \\
\hline
\end{tabular}

Where: $N D V I_{i}$ and $L S T_{i}$ present NDVI and LST values at the period $i$, respectively; $\overline{N D V I}$ presents the multi-year average NDVI at the same period; $N D V I_{\min }$ and $L S T_{\min }$ present the multi-year minimum values of NDVI and LST at the same period, respectively; $N D V I_{\max }$ and $L S T_{\max }$ present and the multi-year maximum values of NDVI and LST at the same period, respectively; a is a weighting factor, default value is 0.5; $E V I_{i}$ presents Enhanced Vegetation Index value at the period $i$.

Table 1. Typical remote sensing drought indices

\subsection{Cloud-based data processing}

Remote sensing drought indices are generated in Google Earth Engine (GEE) which is a cloud platform for geo-spatial data handling. In this platform, the Map/Reduce approach is adopted for handling such a huge among of imagery data. Pixel-based calculation has been employed for getting those indices over the whole nation.

\subsection{Sampling and evaluation}

Considering that the agricultural drought is the most concern, effectiveness of remote sensing drought monitoring on agricultural lands is analysed, especially for the traditional wheat planting region in the north of Kazakhstan. In this study, MODIS land cover type data (MCD12Q1) are utilized to get cropland samples (type code: 12,14 in MCD12Q1 data sets).

To analyse the consistency of various remote sensing drought indices, the relationships among the indices are examined by Pearson's correlation coefficient $(r)$. The formula is shown as follows. In this study, the correlations of those indices at two typical years are tested, e.g., a drought year and a normal year distinguished by annual crop yield statistics.

$$
r=\frac{\sum_{i=1}^{n}\left(x_{i}-\bar{x}\right)\left(y_{i}-\bar{y}\right)}{\sqrt{\sum_{i=1}^{n}\left(x_{i}-\bar{x}\right)^{2}} \sqrt{\sum_{i=1}^{n}\left(y_{i}-\bar{y}\right)^{2}}}
$$

Where, $x_{i}, y_{i}$ are the values of two tested indices at sample pixel $i$, respectively; $\bar{x}, \bar{y}$ are the mean values; $n$ is the sample size.

Besides, a national-scale assessment of remote sensing indices on agricultural drought monitoring is conducted based on annual drought conditions and crop yield. The correlation between 
remote sensing drought index and soil moisture is evaluated. Regional averages over the growing season are utilized. Besides, to measure the validity of remote sensing drought index in agricultural drought monitoring, the variation of remote sensing drought index is compared with the change of annual crop yield, and the relationship is examined by a statistically significant test.

\section{RESULTS}

4.1 Spatial patterns of drought monitoring by remote sensing indices

Based on remote sensing drought indices, agricultural drought monitoring in two different years including a severe drought year (2012) and a normal year (2016) are analysed. Figures 2 and 3 show the results of drought monitoring with different remote sensing indices.

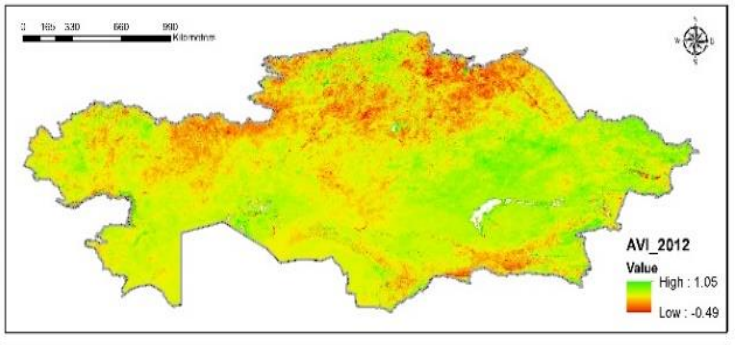

(a)
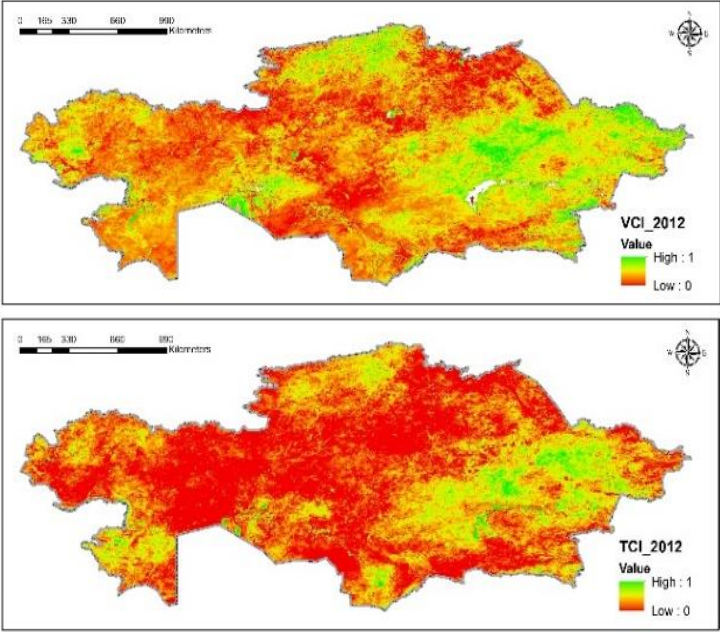

(b)

(c)
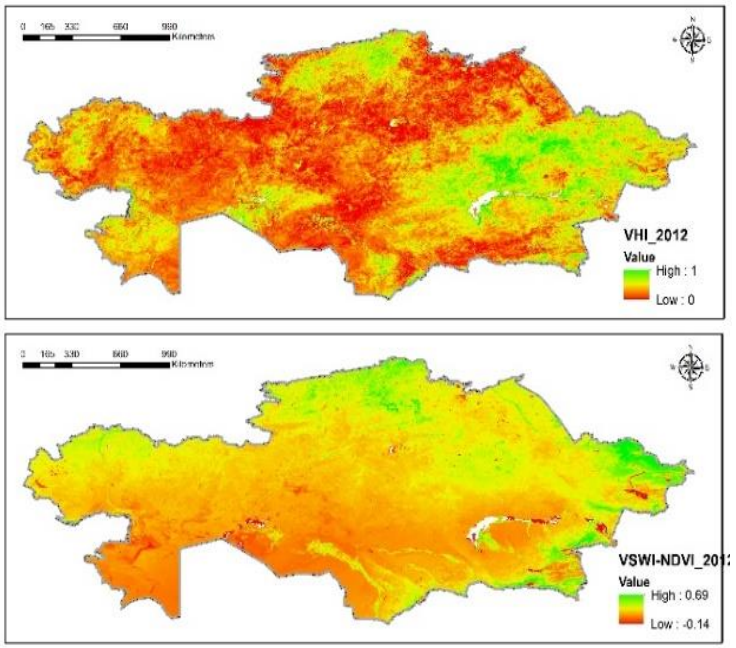

(d)

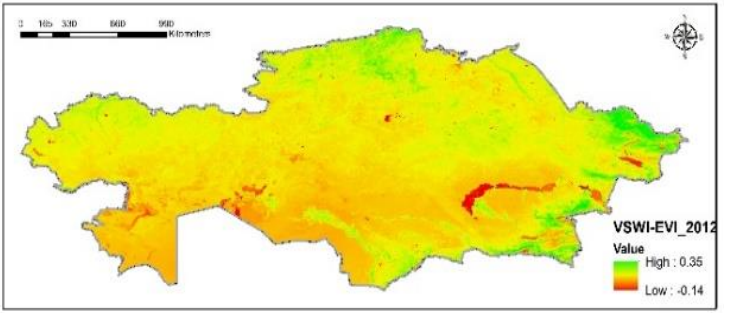

Figure 2. Remote sensing of drought monitoring in a severe drought year (2012), (a) AVI, (b) VCI, (c) TCI, (d) VHI, (e) VSWI-NDVI, (f)VSWI-EVI
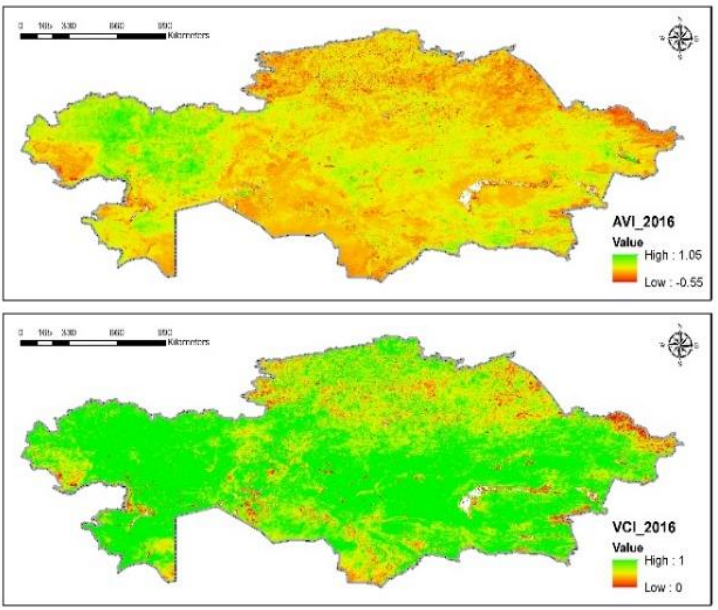

(a)

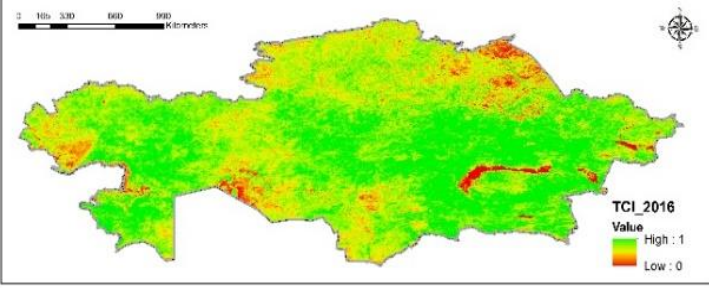

(c)

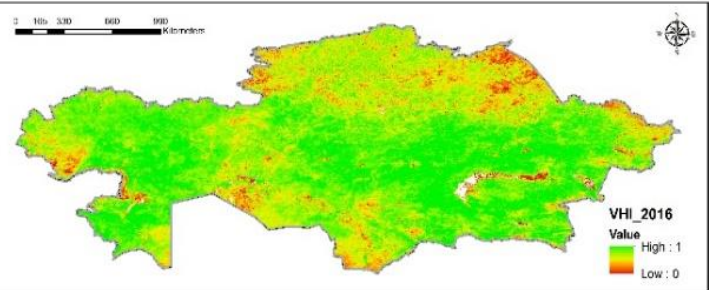

(d)

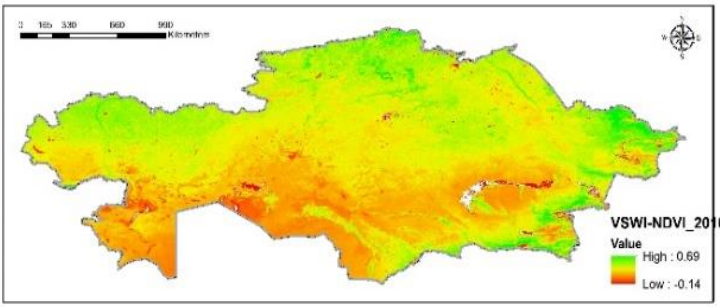

(e)

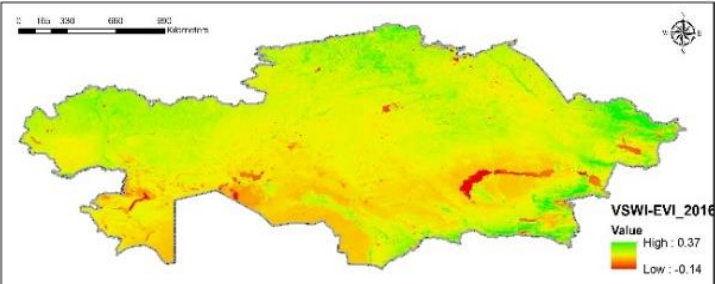

Figure 3. Remote sensing of drought monitoring in a normal year (2016), (a) AVI, (b) VCI, (c) TCI, (d) VHI, (e) VSWI-NDVI, (f)VSWI-EVI 
From the spatial pattern, the spatial consistency of remote sensing-based drought monitoring models is not good enough. Big difference exists in the spatial distribution of the drought. Among them, the pairs of indices with high correlation (e.g., VCI and VHI, NDWI-NDVI and NDWI-EVI) have similar spatial patterns. Besides, vegetation-based indices (e.g., AVI and VCI) have high consistency.

\subsection{Consistency analysis results of remote sensing drought indices}

Table 2 illustrates the results of correlation analysis among the remote sensing indices in a drought year (2012) and a normal year (2016), respectively.

\begin{tabular}{|c|c|c|c|c|c|c|}
\hline $\begin{array}{l}2012 / \\
2016\end{array}$ & AVI & VCI & TCI & VHI & $\begin{array}{l}\text { VSWI- } \\
\text { NDVI }\end{array}$ & $\begin{array}{l}\text { VSWI } \\
\text {-EVI }\end{array}$ \\
\hline AVI & $\begin{array}{l}1.00 / \\
1.00\end{array}$ & & & & & \\
\hline VCI & $\begin{array}{l}0.91 / \\
0.90\end{array}$ & $\begin{array}{l}1.00 / \\
1.00\end{array}$ & & & & \\
\hline TCI & $\begin{array}{l}0.52 / \\
0.38\end{array}$ & $\begin{array}{l}0.61 / \\
0.37\end{array}$ & $\begin{array}{l}1.00 / \\
1.00\end{array}$ & & & \\
\hline VHI & $\begin{array}{l}0.84 / \\
0.82\end{array}$ & $\begin{array}{l}0.94 / \\
0.89\end{array}$ & $\begin{array}{l}0.85 / \\
0.76\end{array}$ & $\begin{array}{l}1.00 / \\
1.00\end{array}$ & & \\
\hline $\begin{array}{l}\text { VSWI- } \\
\text { NDVI }\end{array}$ & $\begin{array}{l}0.61 / \\
0.58\end{array}$ & $\begin{array}{l}0.56 / \\
0.59\end{array}$ & $\begin{array}{l}0.39 / \\
0.22\end{array}$ & $\begin{array}{l}0.55 / \\
0.53\end{array}$ & $\begin{array}{l}1.00 / \\
1.00\end{array}$ & \\
\hline $\begin{array}{l}\text { VSWI- } \\
\text { EVI }\end{array}$ & $\begin{array}{l}0.62 / \\
0.59\end{array}$ & $\begin{array}{l}0.58 / \\
0.61\end{array}$ & $\begin{array}{l}0.45 / \\
0.27\end{array}$ & $\begin{array}{l}0.59 / \\
0.56\end{array}$ & $\begin{array}{l}0.96 / \\
0.95\end{array}$ & $\begin{array}{l}1.00 / \\
1.00\end{array}$ \\
\hline
\end{tabular}

Table 2. Correlation matrix of typical remote sensing drought indices in a drought year (2012) and a normal year (2016)

The results of correlation analysis show that the typical remote sensing drought indices from broad groups do not agree with each other. Among them, the index related to the surface temperature (i.e., TCI) has a poor consistency with other indices except for VHI which has no independence in the correlation analysis. Similar situation occurs in two versions of VSWI (i.e., VSWINDVI, VSWI-EVI).

From the perspective of different years, the consistency of remote sensing drought indices in a drought year is a litter better than that in normal years in general.

\subsection{The response of remote sensing indices to agricultural drought}

Based on time series data, correlation analysis results of remote sensing indices and annual total grain yield as well as soil drought condition implied by soil moisture are shown in Table 3 .

\begin{tabular}{|l|l|l|l|l|l|l|}
\hline & AVI & VCI & TCI & VHI & $\begin{array}{l}\text { VSWI- } \\
\text { NDVI }\end{array}$ & $\begin{array}{l}\text { VSWI- } \\
\text { EVI }\end{array}$ \\
\hline $\begin{array}{l}\text { Drought } \\
\text { condition }\end{array}$ & $0.83^{*}$ & 0.83 & 0.82 & 0.84 & 0.84 & 0.86 \\
\hline Yield & 0.38 & 0.37 & 0.48 & 0.45 & 0.41 & 0.52 \\
\hline
\end{tabular}

Table 3. Correlation of remote sensing drought indices with annual average of soil moisture and total grain yield
From the results, VSWI-EVI shows a higher correlation with soil drought and total grain yield in the study area. Thus, by taking VSWI-EVI as an indicator of drought events monitoring, Figure 4 illustrates the annual variation of total grain yield and remote sensing drought index. The change pattern of remote sensing index (i.e., VSWI-EVI) shows a great consistency with total grain yield in terms of change trend.

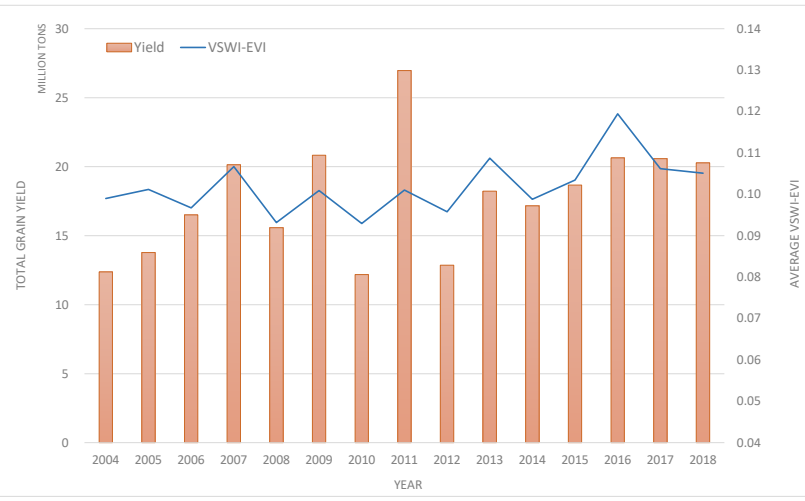

Figure 4. Annual variation of total grain yield and remote sensing drought index (mean VSWI-EVI) from 2004 to 2018

\section{ANALYSIS AND DISCUSSION}

Based on the precipitation data collected by ground stations over the years, researchers pointed out that the northern part of Kazakhstan has become wetter (Hu et al., 2018). According to the previous studies on validation of soil moisture inversion based on remote sensing data, the correlation coefficients of remote sensing indices and in-situ soil moisture measurements range from 0.2 to 0.4 (Song et al., 2017). Further study indicates that NDVI-LST based index such as VSWI has a relative higher correlation with soil moisture in arid lands compared with other indices (Sun et al., 2020). A similar conclusion has been obtained in this study at larger scale of time and space.

This study has also confirmed that the inter-correlations among different types of remote sensing drought indices are not high. The results of agricultural drought monitoring by different remote sensing indexes are not consistent in space. Generally, similar types of drought indices have high consistency, while poor consistency can be observed among different types. Besides, from the observation in a severe drought year and a normal year, there is not an obvious difference of the correlations among those indices in different years. But the temperature-related index (i.e., TCI) is an exception. The correlation of TCI with other indices has changed a lot within the two observation years.

In addition, according to the observation through time series, VSWI-EVI shows a higher correlation with total grain yield that reveals agricultural drought condition. Similar to previous studies, VSWI reflects the overall soil drought situation in the study region according to the correlation analysis result. Besides, VSWI-EVI shows good synchronization with the change of annual crop yield in terms of change trend over year. However, it should be noted that their correlations between remote sensing indices and annual crop yield are based on the limited sample size (e.g., 15-year time series data). More samples from temporal aspect will bring more reliable results. 


\section{CONCLUSION}

This study analysed the consistency of commonly used remote sensing drought indices in Kazakhstan. The effectiveness of those indices in agricultural drought monitoring was tested. The results show that the spatial patterns and consistency of the selected indices are different, and the annual change of remote sensing drought index generally agrees to the change of total grain yield, which means remote sensing can be used for agricultural drought monitoring and drought hazard assessment in this region. Compared with single-factor remote sensing drought model, NDVI-LST based indices are more effective for agricultural drought monitoring given the climatic and vegetation features in arid areas.

In the future, the sensitivity of remote sensing indices to the drought in different periods of growing season will be examined. On the basis of correlation, remote sensing indices would be used to build a model for crop yield estimation.

\section{ACKNOWLEDGEMENTS}

The study was funded by Leading Project of Chinese Academy of Sciences: Pan-Third Pole Environment Study for a Green Silk Road (Pan-TPE) (No.: XDA20060303) and Guangdong Provincial Science \& Technology Plan Project (No.: 2017A050501027).

\section{REFERENCES}

Dubovyk, O., Ghazaryan, G., González, J., Graw, V., Löw, F., Schreier, J., 2019. Drought hazard in Kazakhstan in 2000-2016: a remote sensing perspective. Environmental Monitoring and Assessment, 191, 510.

Hu, Z., Chen, X., Chen, D., Li, J., Wang, S., Zhou, Q., Yin, G., Guo, M., 2018. Dry gets drier, wet gets wetter: a case study over the arid regions of Central Asia. International Journal of Climatology, 1-20.

Liu, X., Zhu, X., Pan, Y., Li, S., Liu, Y., Ma, Y., 2016. Agricultural drought monitoring: Progress, challenges, and prospects. Journal of Geography Science, 26(6), 750-767.

Mu, L., 2006: Suitability and Uncertainty Analysis of Agricultural Drought Indicator with Remote Sensing. PhD Dissertation. Chinese Academy of Sciences, Beijing.

Rhee, J., Im, J., Carbone, G.J., 2010. Monitoring agricultural drought for arid and humid regions using multi-sensor remote sensing data. Remote Sensing of Environment, 114, 2875-2887.

Ta, Z., Yu, R., Chen, X., Mu, G., Guo, Y., 2018. Analysis of the spatio-temporal patterns of dry and wet conditions in Central Asia. Atmosphere, 9, 7.

Song, Y., Fang, S., Liang, H., et al., 2017. Comparison and application of agricultural drought indexes based on MODIS data. Remote Sensing for Land \& Resources, 29(2), 215-220.

Sun, B., Qian, J., Chen, X., Xing, X., Zhou, Q., 2020. Consistency and comparison among remote sensing drought indices and SMAP soil moisture in Kazakhstan. Arid Zone Research, 37(3), 663-670.

Sun, H., Chen, Y., Sun, H., 2012. Comparisons and classification system of typical remote sensing indexes for agricultural drought. Transactions of the Chinese Society of Agricultural Engineering (Transactions of the CSAE), 28(14), 147-154.

Zhang, L., Wang, Y., Chen, Y., 2020. Spatial and temporal distribution characteristics of drought in Central Asia based on SPEI index. Arid Zone Research, 37(2), 282-290. 